\title{
Evaluating the Performance Indices of Tourist Service agency in Zahedan Using Decision-Making TOPSIS Model
}

\author{
Elyas Sarhadii $^{1 *}$, Fahimeh Shahraki ${ }^{2}$ \\ MA student of Geography and Tourism planning, faculty of humanities, Islamic Azad university, \\ Zahedan branch, Zahedan, Iran
}

\begin{abstract}
In today's world that increasingly goes toward service-based economy, the high quality services lead to satisfaction and revisiting of tourists in tourism industry. Travel and tourism agencies act as an intermediary element between the main suppliers of services such as tour operators or transport companies and hotels on one hand and the tourists willing to travel and tourism on the other hand. They are actually considered as the frontline of tourism industry facing with the applicants. This study was performed to evaluate and rank the travel agencies in terms of facilities and the impact of these agency s on attracting tourists. Currently, 25 agencies are working in the city of Zahedan. The Topsis weighting method was used to prioritize the tourism services agency s. The agencies with "A" and "C" licenses, having the score of 0.789 , have a very eligible situation in terms of studied indices. These indices have an eligible condition with the score of 0.743 regarding agencies with "A", "B" and "C" licenses. The agencies with "A" and "B" licenses with a score of 0.593 are considered somewhat eligible, while agencies with "A" licenses with a score of 0.170 have not an eligible situation compared to the other three types.
\end{abstract}

Keywords: Zahedan, Topsis decision-making model, Travel agencies, Tourism

\section{INTRODUCTION}

Benefiting from simultaneous unique privileges, tourism industry provides several objectives in the national level of a country, while other industries are individually responsible for providing some of these desired goals. Thus, focusing on this industry is of great importance and has a special place in national and international equations (Kazemi et al., 2011, 2). The need to leisure time is among basic human needs such as working, eating and sleeping (Rahnamai, 1997, 209-210). Tourism, in its spatial patterns (urban, rural, nature, etc.) moves towards a "Tourism Village" in a process of globalization, seems to be like a common free market that all countries will benefit from based on their efforts (Baidal, 2003, 131). Today's world increasingly goes toward a service-based economy. Nowadays, the services are regarded as the heart of value creation in the economy, and services are in the focus of every society economic activities (Shariati and Frozan, 2011,2). Service is a subtle and impalpable activity or interest that one party provides for the other party, and is not followed by ownership of anything. Generating service may or may not be dependent to physical goods (Karim Soltani, 2014: 18). From a management perspective, although some studies argue, there is no direct correlation between tourists' satisfaction and attractions, facilities and services (Chen and et al, 2011, 13), but it is generally believed that high quality of service providing in tourism leads to satisfaction and revisiting of tourists. Meanwhile, from a long time ago, travel services agencies have played the retailer role in the tourism industry so that agencies are the ultimate ring in the process of consuming the products of this industry that receive these services and connect the products with the source providing of these services and products (Lamseden, 2008: 265). Travel and tourism agencies act as an intermediary element between the main suppliers of services such as tour operators or transport companies and hotels on one hand and the tourists willing to travel and tourism on the other hand. They are actually considered as the frontline of tourism industry facing with the applicants. Success or failure of these interfaces is highly effective on the success or failure of programs for tourism destinations and tourism service providers (Iman Khan et al., 2014: 2). The 
travel agencies place, as the link between tourists and tourism environment plays a significant role in overcoming the existing problems in the province of Sistan and Baluchestan. Evaluating the qualitative and quantitative status of regarding services to passengers and tourists as well as measurement the factors affecting the performance of travel agencies, including tourists' and customers' satisfaction of the agencies products, accountability, credibility and assurance, customer relationship, apparent situation of agency s and use of technology are as the goals of this study. Using an integrated and coherent approach of structural equations modeling, the research seeks for the answer of this question:

Is there any relationship between the capability and ability of agencies and the satisfaction rate of tourists in the city of Zahedan or not?

\section{THE THEORIES}

The increasing growth of the tourism industry has caused many experts call the twentieth century as the century of tourism. According to tourism authorities, at the end of the twentieth century and twenty-first century a revolution will be occurred in tourism a revolutionary which its waves in the world economy will be effective (Kazemi, 2006, 3). This industry more than any other industry has caused the movement of capital and money transfer and currency in local, regional, national and international scale (Tavalli, 2006,15). Tourism in the present day, as the industry without smoke has many capabilities and fans. Significant and impressive growth of tourism in the last fifty years shows the economic and social importance of this phenomenon. According to estimation of the World Tourism Organization, Total tourism in the world in 1950 was almost 250 million people and in 2000 the figure was 700 million and in 2020 it will reach to about one billion and 600 million people, these figures represent a growth of 7 percent in a fifty-year period (1950-2000). In addition, income from tourism in 1980 amounted to 105 billion dollars that the figure has reached to 476 billion dollars in 2000 (Kazemi,2006,4). The tourism industry in the early years of the twentyfirst century has become to a major economic activity and it is one of the most lucrative industries and employment in the world. In 2002, revenue from international tourism amounted to seven hundred and two billion dollars (Monshizadeh and Moradi, 2005, 72).

Nowadays, Tourism within the framework of logistics projects both at the national, regional and local level is considered as one of the tools for the development and fighting against poverty. Tourism which is the most important factor for regional development is a balancer and lucrative activity and it is followed by economic and social development at the regional level and equitable distribution of income and employment (Shokoi, 2008, 12). This industry can play a major role in strengthening the local people and diversifying economic growth and creating employment opportunities for the rural population in relation to other economic sectors. Tourism industry is considered as the largest and most diverse industry in the world. Many countries know this dynamic industry as the main source of income, employment and as a way of infrastructure and private sector development. Today, sustainability is accepted widely as the fundamental approach for any development including tourism development and at the political and environmental issues, sustainable tourism as a new concept, has been proposed to deal with the negative effects of tourism development (Koussis, 2000, 27). Thus, the concept of sustainable tourism covers the social, economic and environmental aspects but it is always emphasized on the environment and from prospective of some people, this type of tourism has been proposed as the opposite of tourism massively.

Sustainable tourism development is the main topics of economic sustainability including the diversification of the local economy, controlled economic growth, improving of local and regional relations and equitable distribution of economic resources in local economy. The economic dimension of sustainable tourism implies on suitable income, stability of prices, goods and services and equality of employment opportunities in society (Mccool, 1995,29). Environmental sustainability dimension implies on the combination of environmental factors and their interactions 
with tourism resources which should not be affected by changes (Ibid, 28). In sustainable tourism, it implies on social and cultural sustainability to social identity and social capital and attention to the culture of society and its privileges and attention to reinforcing of social performance and selfesteem which will allow residents to control their lives (Chohi, 2003, 33).

\section{AREA OF STUDY}

Zahedan is the capital of as the largest province in the country. Zahedan is limited to Sistan from the north, Kerman from the west, Pakistan from the east and Khash city from the south. According to the 2011 census, it has 575,116 inhabitants. The area of Zahedan is 8123 of which, about 20 percent i.e. 1325 hectares are old texture back more than 30 years. The south and southwest of the city is tall while its height is reduced by moving to the north. The city has Three urban districts. The following figure has shown the geographical location of Zahedan city (General Governor of Sistan and Baluchistan, 2011).

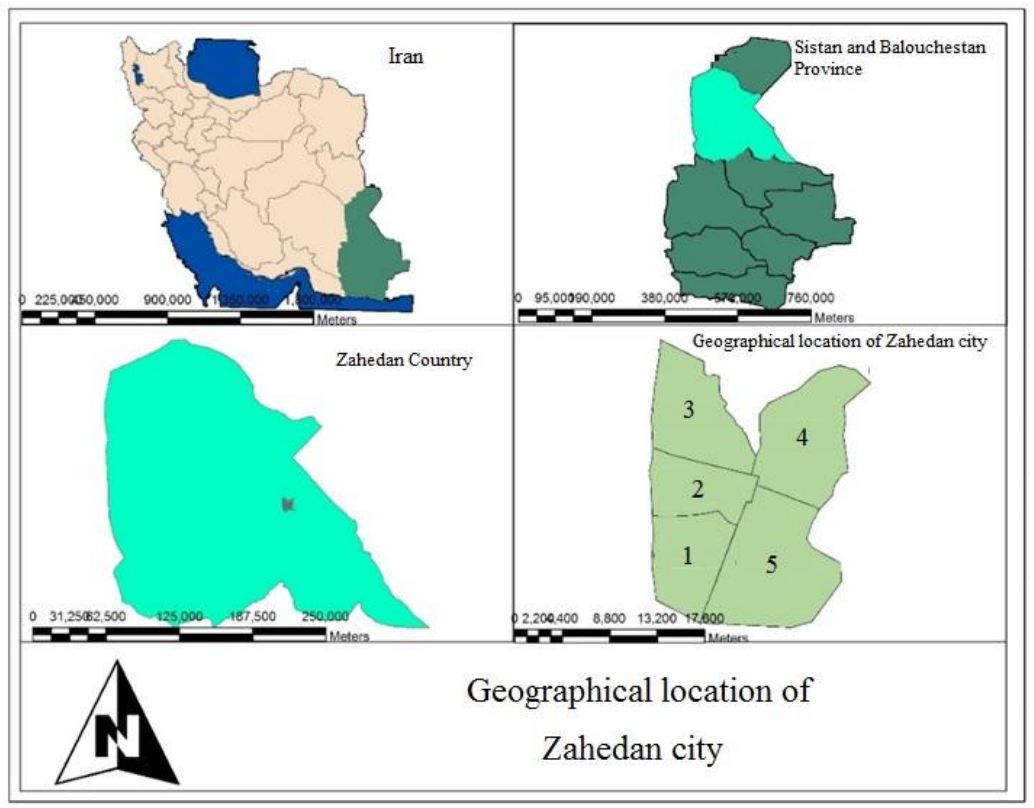

Figure (1): Location the city of Zahedan

\section{RESEARCH METHODOLOGY}

The research methodology was a descriptive-analytical approach, in which the data was collected based on a combination of documentary (library) and surveying studies. The library method was used in the documentary studies to understand the problem framework aimed to develop theoretical foundations and basic concepts of the research subject. In this method, the findings of other research were collected and analyzed through the study of available domestic and foreign resources. In the survey studies, according to the main objective of research and developed hypotheses, a researcher observation technique and a questionnaire were used for evaluation and prioritization of tourism agency s active in the city of Zahedan as well as for assessing the relationship between the agencies capability and attracting tourists. The research population included all the agency $\mathrm{s}$ and tourist agencies of Zahedan, which now include 25 working agencies. Also, five tourists were selected from each agency to assess the services and capabilities of agencies from the tourists' perspective with a total of 125 people. Since the purpose of research was to determine the causal relationships between the independent variables and mediator and ultimate dependent variables, then, the research was an applied type in terms of purpose and a causal-comparative study regarding the method of data collection by using a structural equations model. A questionnaire was used as the main data collection tool. Accordingly, 32 questions with a 5-point Likert scale were considered to measure all the research variables. The location territory of research was the city of Zahedan and 
its travel and tourism agencies. Thus, the study population were customers who are present at the time of sampling in these agency s. Descriptive statistical methods were used to prepare charts and tables related to independent and dependent variables. Pearson's correlation coefficient and simple linear regression were used to evaluate the status of tourism agency $s$ and agencies from the respondents' point of view.



Figure (2): Research conceptual model

In this study, 30 questionnaires were distributed in the first phase among the population for validity and reliability assessment. One of the main objectives was to evaluate the clarity and reliability of posed questions. After analyzing the results, the coefficient of 0.8 was obtained, which demonstrated a high reliability and validity of the questions raised in the questionnaire.

\section{TOPSIS model}

In this model, it is assumed that the suitability of each index is monotonically increasing or decreasing. This measurement is based on an eleven-point scale that zero and 10 are the lowest and highest values, respectively. It should be noted that values such as 2, 6, 4 and 8 are intermediate values between the two other values, and values of zero and ten are less used. This measurement is done with these three assumptions:

- For example, the distance between very low and low is equal to the distance between high and very high.

- It is assumed that a score of 9 is three times higher than the score of 3 .

- Combining values is allowed for various indices; since, the difference between every two specific values, for any given index, is the same.

These three assumptions transform the ordinal scale into an interval scale. 


\section{RESULTS AND DISCUSSION}

\section{Evaluating the Performance Indices of Tourist Service agency in Zahedan Using Decision-} Making TOPSIS Model

Table (1): Quantitated and scale-less decision-making matrix

\begin{tabular}{|c|c|c|c|c|c|c|}
\hline Index & $\begin{array}{c}\text { Technology } \\
\mathrm{C}_{1}\end{array}$ & $\begin{array}{c}\text { Credit and } \\
\text { guarantee } \\
\mathrm{C}_{2}\end{array}$ & $\begin{array}{c}\text { Accountability } \\
\mathrm{C}_{3}\end{array}$ & $\begin{array}{c}\text { Appearance } \\
\mathrm{C}_{4}\end{array}$ & $\begin{array}{c}\text { Customers } \\
\text { relationship } \\
\mathrm{C}_{5}\end{array}$ & $\begin{array}{c}\text { Products } \\
\mathrm{C}_{6}\end{array}$ \\
\hline $\mathrm{A} \& \mathrm{C}$ & 6 & 3 & 8 & 9 & 7 & 8 \\
\hline $\mathrm{A} \& \mathrm{~B}$ & 5 & 7 & 5 & 8 & 6 & 5 \\
\hline $\mathrm{A}$ & 3 & 6 & 6 & 3 & 3 & 5 \\
\hline $\mathrm{A} \& \mathrm{~B} \& \mathrm{C}$ & 7 & 5 & 4 & 7 & 9 & 9 \\
\hline
\end{tabular}

Every problem may have several indicators. Therefore, knowing the relative importance of the indicators seems to be necessary. Thus, any index is given a weight so that the sum of the weights of indices would be equal to 1 . There are different methods for assessment the weights of indices. We have chosen Shannon entropy method for this purpose. This method can be used when the data of a decision-making matrix is fully specified. The idea of this method suggests that higher dispersion in the values of an index leads to its higher importance. In this connection, the first element (pij) has more significance (Taherkhani, 2008). To calculate the entropy, first, each row of the decision-making matrix is divided by its sum.

Equation (1):

$$
p_{i j}=\frac{a_{i j}}{m} \quad p_{i j}=\frac{1}{n} \rightarrow \frac{6}{22}=0 / 273
$$

Table (2): The obtained pij

\begin{tabular}{|c|c|c|c|c|c|c|}
\hline Agency s & C1 & C2 & C3 & C4 & C5 & C6 \\
\hline A\&C & 0.273 & 0.182 & 0.348 & 0.333 & 0.214 & 0.296 \\
\hline A\&B & 0.227 & 0.318 & 0.217 & 0.296 & 0.231 & 0.185 \\
\hline A & 0.182 & 0.273 & 0.260 & 0.111 & 0.154 & 0.185 \\
\hline A\&B\&C & 0.318 & 0.227 & 0.174 & 0.259 & 0.259 & 0.333 \\
\hline
\end{tabular}

In this formula, $\mathrm{k}$ as the constant value, is calculated as follows, where, $\mathrm{m}$ is the number of sample areas or studied options:

Equation (2):

$$
k=\frac{1}{\ln (m)}
$$

$$
k=\frac{1}{\ln (4)}=0 / 721
$$

After obtaining the entropy coefficient $(\mathrm{k})$, the entropy of index $\mathrm{j}^{\text {th }}$ will be calculated as follows: Equation (3):

$$
\begin{aligned}
& E_{J}=-K \sum_{i=1}^{m}\left(P_{i j} \ln P_{i j}\right) \\
& E_{J}=-0 / 721((0 / 273 \ln (0 / 273)+(0 / 227 \ln (0 / 227)+(0 / 182 \ln (0 / 182)+(0.318 \ln (0.318)=0 / 984
\end{aligned}
$$


To obtain dj, the following formula would be used:

Equation (4):

$$
d_{j}=1-E_{j} \quad d_{j}=1-0.984=0 / 016
$$

Then, the value of $\mathrm{Wj}$ weight is obtained as follows:

Equation (5):

$$
W_{j}=\frac{d_{i}}{\sum d_{i}}=\frac{0.016}{0.159}=-0.101
$$

Table (3): Scale-less N matrix

\begin{tabular}{|c|c|c|c|c|c|c|}
\hline C6 & C5 & C4 & C3 & C2 & C1 & \\
\hline 0.974 & 0.971 & 0.952 & 0.976 & 0.984 & 0.984 & $\mathrm{E}_{\mathrm{J}}$ \\
\hline 0.026 & 0.029 & 0.048 & 0.024 & 0.016 & 0.016 & $\mathrm{~d}_{\mathrm{ij}}$ \\
\hline 0.164 & 0.182 & 0.302 & 0.151 & 0.101 & 0.101 & $\mathrm{~W}_{\mathrm{i}}$ \\
\hline
\end{tabular}

Now, the scale-less weighted matrix can be achieved. For this purpose, the scale-less matrix is multiplied in the square matrix $(\mathrm{Wn} \times \mathrm{n})$ that its main elements are the weights of indices and its other elements are zero. The resulting matrix is called scale-less weighted matrix displayed with V. The operation is as follows:

Equation (6):

$$
\mathrm{V}=\mathrm{N} \times \mathrm{W}_{\mathrm{n} \times \mathrm{n}}
$$

Table (4): Calculating the score for each of the components to be multiplied by the matrix

\begin{tabular}{|l|l|l|l|l|l|l|}
\hline Agency s & $\mathrm{C} 1$ & $\mathrm{C} 2$ & $\mathrm{C} 3$ & $\mathrm{C} 4$ & $\mathrm{C} 5$ & $\mathrm{C} 6$ \\
\hline A\&C & 0.574 & 0.356 & 0.674 & 0.632 & 0.519 & 0.573 \\
\hline A\&B & 0.445 & 0.624 & 0.421 & 0.561 & 0.445 & 0.358 \\
\hline A & 0.365 & 0.534 & 0.505 & 0.211 & 0.296 & 0.358 \\
\hline A\&B\&C & 0.624 & 0.445 & 0.339 & 0.491 & 0.667 & 0.644 \\
\hline
\end{tabular}

Table (5): Weighted scale-less matrix of $\mathrm{V}$

\begin{tabular}{|c|c|c|c|c|c|c|}
\hline Agency s & C1 & C2 & C3 & C4 & C5 & C6 \\
\hline A\&C & 0.054 & 0.036 & 0.102 & 0.191 & 0.094 & 0.094 \\
\hline A\&B & 0.045 & 0.063 & 0.064 & 0.169 & 0.081 & 0.059 \\
\hline A & 0.036 & 0.054 & 0.076 & 0.064 & 0.054 & 0.059 \\
\hline A\&B\&C & 0.063 & 0.054 & 0.051 & 0.148 & 0.121 & 0.106 \\
\hline
\end{tabular}

Determining positive ideal solution and negative ideal solution

Positive and negative ideal solutions are defined as follows:

$(\mathrm{VJ}+)$ Positive ideal solution $=$ [Vector of the best values of each $\mathrm{V}$ parameter matrix $]$

$(\mathrm{VJ}-)$ Negative ideal solution $=[$ Vector of the worst values of each $\mathrm{V}$ parameter matrix $]$

Equation (7):

$$
\begin{aligned}
& J^{+}=\left[\min V J_{11}, \max V_{J 2}, \max V_{J 3}, \max V_{J 4}, \max V_{J 5} \max V_{J 6}\right] \\
& J^{-}=\left[\max V J_{11}, \min V_{J 2}, \min V_{J 3}, \min V_{J 4}, \min V_{J 5} \min V_{J 6}\right] \\
& \boldsymbol{J}^{+}=[0.036,0.063,0.102,0.191,0.121,0.106] \\
& \boldsymbol{J}^{-}=[0.063,0.036,0.051,0.064,0.054,0.059]
\end{aligned}
$$


The best values for positive and negative indices are the largest and smallest amounts, respectively, while the worst values for positive and negative indices are respectively the smallest and largest amounts.

The distance of each option to the positive and negative ideal

To obtain the distance of each option

The following formula was used to obtain the distance of each option to the positive and negative ideals.

Equation (8):

The distance from positive ideal:

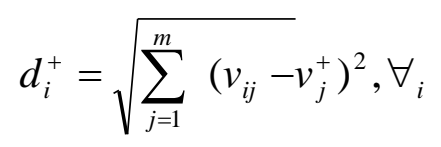

Equation (9):

The distance from the negative ideal: $\quad d_{i}^{-}=\sqrt{\sum_{j=1}^{m}\left(v_{i j}-v_{i}^{-}\right)^{2}}, \forall_{i}$

To evaluate the performance of tourism agency s in Zahedan, a questionnaire was developed based on relevant criteria and indicators and completed by visitors of these agency s. In this regard, first, five evaluation indices of these agency s, which are a combination of the indicators examined in this study were evaluated among travel and tourism agencies of Zahedan, which were divided into four categories based on their type of activity and licenses. According to this scale, 1 and 9 respectively show the lowest and highest rates. We converted their qualitative scores to quantitative scores, which are shown in Table 5.

After the quantitating the indices, to make different scales of measurement comparable, the scaleless making method had to be used. Doing this, the values of different indices were made dimensionless and additive. In this part, scale-less making by using normalization was applied. In this type of scale-less making, each element of the decision matrix is divided by the square sum of the squares of each row in the quantified table. In this way, all the rows of the decision-making matrix would have a similar unit, and thus, they can be easily compared with each other. In this section, according to the briefing principle, one of the items is stated for instance.

Equation (10):

$$
n_{i j}=\frac{a i j}{\sqrt{\sum_{i=1}^{m} a i j^{2}}} n_{i j}=\frac{6}{\sqrt{\left(6^{2}+5^{2}+4^{2}+7^{2}\right)}}=0 / 574
$$

Table (6): Scale-less making by using the Norm

\begin{tabular}{|c|c|c|c|c|c|c|}
\hline Agency s & C1 & C2 & C3 & C4 & C5 & C6 \\
\hline A\&C & 0.574 & 0.356 & 0.674 & 0.632 & 0.519 & 0.573 \\
\hline A\&B & 0.445 & 0.624 & 0.421 & 0.561 & 0.445 & 0.358 \\
\hline A & 0.365 & 0.534 & 0.505 & 0.211 & 0.296 & 0.358 \\
\hline A\&B\&C & 0.624 & 0.445 & 0.339 & 0.491 & 0.667 & 0.644 \\
\hline
\end{tabular}

As the results indicate, the status quo of agency s with "A" and " $\mathrm{C}$ " licenses tends to 1 , which suggests that they are in a very eligible situation in terms of studied indicators. This evaluation appears to be eligible in case of agency s with "A", "B" and "C" licenses and relatively good regarding agency $\mathrm{s}$ with "A" and "B" licenses. But agency s with "A" licenses do not have a 
DOI : https://dx.doi.org/10.26808/rs.aj.i6v1.12

American Journal of Sustainable Cities and Society

Issue 6, Vol. 1 January- December 2017

Available online on http://www.rspublication.com/ajscs/ajsas.html

ISSN $2319-7277$

favorable situation compared to other three types. According to the formula $(0 \leq \mathrm{R} \leq 1)$, the results achieved have been clearly expressed in the following:

Table (7): Final ranking of the status of agency s based on their licenses

\begin{tabular}{|c|c|c|c|c|}
\hline Row & Agency s & $\begin{array}{c}\text { Priority } \\
\text { factor }\end{array}$ & Eligibility & Agency s \\
\hline 1 & A\&C & 0.783 & Very favorable & Ahuran, Maka, Mahkan, Ara, Makran, Pasargad \\
\hline 2 & A\&B & 0.591 & $\begin{array}{c}\text { Relatively } \\
\text { favorable }\end{array}$ & Oshida, Daz, Saba Seyr Shargh, Farasir, Hamoon Parvaz \\
\hline 3 & A & 0.170 & Unfavorable & $\begin{array}{r}\text { Ghoghnoos, Homa Yaran, Homay Mehri, Zahedan Paravz, Arikeh, } \\
\text { Awat Shokoh Pars, Parth, Iran Air, Nakhle Sabz }\end{array}$ \\
\hline 4 & A\&B\&C & 0.743 & Favorable & Hamoon Aral, Homatis, Moazzen, Khaterat, Taftan Tour \\
\hline
\end{tabular}

\section{Conclusion}

Tourism agencies should pay attention to all steps of providing services in the service delivery process. Tourism agencies, as one of the tourism service providers, need to be in continuous communication with their customers and informed of their opinions. Optimal quality of services can be ensured when the customer's expectations of service have been met or something beyond his expectation has been presented. Rapid development and growth of service industries during the last two decades has increased the competition among companies to providing the best customers service and maintaining them. The best services are defined as high quality of services provided to clients. According to the potentials in the city of Zahedan and its tourism agencies, study the factors affecting the quality indices of services provided to customers by tourism agencies appears to be necessary. Therefore, the present study was done to evaluate the factors effective on service quality indicators in Zahedan tourism agencies. Its aim was to assess the impact of factors such as the product characteristics (service), accountability, customer relationship, appearance, use of technology, credit and the guarantee. In general, the correlation coefficient results indicated that there is a correlation between the capability and ability of tourism service agency s in Zahedan and the tourists' satisfaction (0.378), and this correlation is statistically significant. Also, according to the $\mathrm{T}$ test obtained as 3.65 , one can conclude that according to the respondent subjects, it seems that the overall condition of the travel agencies performance in the city of Zahedan occurs in the satisfaction area of people. After collecting data, they were put in the ranking model format based on similarity to the ideal solution. Then, based on Topsis model, the travel agencies were finally ranked based on selected indicators and the agencies' performance was analyzed. The results showed that Ahuran, Maka, Mahkam, Ara, Makran and Pasargad agencies had a very desirable priority.

Different studies have been carried out on the role of travel agencies in the tourism industry. In an article entitled as "Study the role of agency s of tourism services in attracting tourists and tourism industry development", Ashrafi concluded that through creating facilities and requirements of tourists, they can be satisfied and by attracting large numbers of tourists, the ground of economic development in the country can be provided. In their study on the impact of providing information about tourism by Tehran travel agencies on developments of Tehran spatial system tourism, Shafiee Sabet et al. (2013) came to the conclusion that the share of travel agencies in the city of Tehran occurs to be as endogenous factors in the spatial system tourism in Tehran region and the role of its functional-structural developments is more than government agencies responsible for tourism as exogenous factors. In an article entitled as "Analysis of the role of travel agencies and restaurants in the city of Isfahan by using tourism development index", Abolhasani et al. (2012) prioritized these agency s and restaurants in four levels. In an article entitled as "The role of travel agencies in planning to reduce the environmental- tourism effects", Saadat and Mokhtari Malekabadi (2014) concluded that the city of Isfahan, despite having diverse cultural, historical, religious and ecotourism attractions does not benefit from a worthy place in the international arena in terms of 
revenue from tourism. In general, the statistics revealed a low position for Iran's tourism industry and Iran's one percentage share of the global tourism portfolio. Most of the results are in order to of this study.

\section{REFERENCES}

- Abolhasani, F., Varesi, HR., Darabi, M., (2012); Analysis the role of travel agencies and restaurants in the city of Isfahan by using tourism development index, Tourism geo-spatial Journal, Volume 1, Issue 1.

- Ashrafi, E., (2013), Study the role of tourism service bureau in attracting tourists and tourism industry development, First tourism and ecotourism congress in Iran

- Baidal, A. Ivars. Josep. (2004), Tourism planning in Spain: evolution and perspective. Annals of tourism research. University of Alicante, Spain. VOL. 31. NO.2. P.330

- Chen, CM, Lee, HT, Chen, SH, Huang, TH (2011), Tourist behavioral intention to service quality and customer satisfaction in Kinmen National Park, Taiwan", International Journal of Tourism Research, 13, 416-432.

- Choi- Ho, Ch, (2003) Managerial problems of Rural Tourism in korea, Food and Fertilizer Technology Center, Taiwan.

- General Governor of Sistan and Baluchistan, (2011).

- Iman Khan, N., Ikani, S., Fakharian, A., (2014); Study the effect on customer- customer interactions on satisfaction, loyalty and word of mouth advertisement (Case study: Travel and tourism agencies of Semnan), Journal of Management, Issue 32

- Karimi Soltani, P., (2014), Effects of tourism on the structure of agriculture in touristic rural regions, First National Conference on Tourism, Geography and environmental sustainability, Shahid Mofateh University, Hamadan

- Kazemi. M, 2006, Tourism management, first edition, publication of the Ministry of Culture and Islamic Guidance, Tehran.

- Kousis, M, 2000, Tourism and the environment; A social Movements perspective; Annals of Tourism Research; Vol.27; No.2;2000.

- Lemsden, L., (2008), Tourism marketing, Translation by Goharian, A., Tehran, Cultural Research Bureau

- Mc cool, S.F, (1995), Linking Tourism, The Environmental and Concepts of Sustainabilty: setting the stage. Forest servis, intermountain Research station.

- Monshizada. R, Moradi. A, (2005), Religious tourists impact on the physical space of the city of Mashhad, Journal of Earth Sciences, No. 11.

- Rahnamaee, MT., (2000), Iran's Environmental Capabilities, Ministry of Housing and Urban Development Press, Tehran

- Saadat, Y., Mokhtari Malekabadi, R., (2014); The role of travel agencies in planning to reduce the environmental impact of tourism, The first national conference on architecture and sustainable urban spaces, Mashhad

- Shariati, AH., Frozan, N., (2011); Factors affecting service quality indicators in the tourism agencies of southern Isfahan, Quarterly Tourism Studies, No. 14

- Shokoi. H, (2008), New approaches in urban geography (first volume), SAMT publications, the eleventh edition, Tehran.

- Taherkhan, M., 2008; Application of TOPSIS technique in spatial prioritizing of agricultural processing industry establishment in rural areas, Economic Research, Issue 3

- Tavalai. S, (2006), An overview of the tourism industry, first edition, Tarbiat Moallem University press, Tehran. 